Revista Tecnologia e Sociedade, Curitiba, v. 11, n. 23, 2015

ISSN (versão online): 1984-3526

ISSN (versão impressa): 1809-0044

\title{
Árvores potenciais a danos urbanos: manejo através da tecnologia, educação e mobilização social
}

\author{
Potential trees to urban damage: management by technology, education and social \\ mobilization
}

\author{
Otacilio Antunes Santana ${ }^{1}$ \\ Nathaly Karoline Bezerra Santos ${ }^{2}$ \\ Myllena Matias da Silva ${ }^{3}$ \\ Rárikmilkrai Lima de Morais ${ }^{4}$ \\ José Imaña Encinas ${ }^{5}$
}

Artigo submetido em jan./2015 e aceito para publicação em mai./2015.

\section{RESUMO}

A coexistência das árvores no ambiente urbano depende de um manejo adequado. A tecnologia, educação e a mobilização social podem ser fatores de eficiência nesta coexistência. Então, o objetivo deste trabalho foi reduzir o número de casos de danos ocasionados por árvores em ambientes urbanos da cidade do Recife, através deste tripé metodológico. Para isso, um aplicativo foi construído para diagnosticar o grau de risco do indivíduo arbóreo para as edificações e vias públicas. O aplicativo foi disseminado através de cursos de capacitação para uma mobilização social com esta temática. Cerca de duas mil árvores foram mobilizadas através do aplicativo, em que a maioria $59 \%$ necessitava de algum manejo. Em 18 meses (de novembro de 2012 a abril de 2014), houve a redução de $85 \%$ de queda de árvores nas áreas avaliadas, mostrando a eficiência do tripé metodológico proposto.

Palavras-Chave: Aplicativo; Algoritmo; Urbanidade, Gestão Ambiental.

\begin{abstract}
The coexistence of trees in the urban environment depends on appropriate management. Technology, education and social mobilization can be efficiency factors in this coexistence. So, the objective of this work was to reduce the number of damage cases caused by trees in urban environments in Recife, through this methodological tripod. For this, application software was built to diagnose the degree of tree risk for individual buildings and public roads. The application software was disseminated through training courses for social mobilization in this topic. About two thousand trees were mobilized through the application software, in which most 59\% required some management. In 18 months (from November 2012 to April 2014), there was a 85\% reduction of tree falls in evaluated areas, showing the efficiency of the proposed methodological tripod.
\end{abstract}

Keywords: Application software; Algorithm; Urbanity, Environmental Management.

\footnotetext{
1 Doutor em Ciências Florestais, Professor Adjunto, Departamento de Biofísica e Radiobiologia, Centro de Ciências Biológicas, Universidade Federal de Pernambuco. E-mail: otacilio.santana@ufpe.br, otaciliosantana@gmail.com.

${ }^{2}$ Graduanda em Ciências Biológicas (Licenciatura), Universidade Federal de Pernambuco. Bolsista do Programa Institucional de Bolsas de Extensão (PIBEX/UFPE).

${ }^{3}$ Graduanda em Ciências Biológicas (Licenciatura), Universidade Federal de Pernambuco. Bolsista do Programa Institucional de Bolsas de Inovação Tecnológica (PIBITI/UFPE).

${ }^{4}$ Graduando em Ciências Biológicas (Licenciatura), Universidade Federal de Pernambuco. Bolsista do Programa Institucional de Bolsas de Extensão (PIBEX/UFPE).

5 Doutor em Ciências Florestais, Professor Titular, Departamento de Engenharia Florestal, Faculdade de Tecnologia, Universidade de Brasília.
} 
Revista Tecnologia e Sociedade, Curitiba, v. 11, n. 23, 2015

ISSN (versão online): 1984-3526

ISSN (versão impressa): 1809-0044

\section{INTRODUÇÃO}

A arborização urbana surgiu de quatro maneiras: pela ocupação humana em ambientes florestais nativos existentes no local, pela arborização sistemática baseada em um projeto de urbanização, pelo plantio ocasional de algum morador local ou pelo processo de disseminação natural das plantas (YANG, 2012). Independente do modus em que as plantas apareceram a presença arbórea traz algumas características: i) beleza cênica (PERKINS et al., 2011), ii) contribuição no microclima (YANG, 2012), iii) produção de frutas local (HLADNIK; PIRNAT, 2011), e iv) alguns transtornos (JIM, 2005).

$\mathrm{Na}$ literatura corrente não científica e na científica, os indivíduos arbóreos já foram noticiados e registrados como causadores de danos materiais devido a sua queda sobre carros, casas e redes elétricas, sua obstrução de estradas e vias de escoamento público, racha e quebra de calçamento público e outros (HLADNIK; PIRNAT, 2011). Esta queda da árvore se dá pela idade do indivíduo arbóreo, presença de insetos que provocam a oquidão e perda de material lenhoso, ventos e inundações decorrentes de condições meteorológicas, e ao uso antrópico em geral (HORÁK, 2011). Outros fatores também poderiam ser elencados, como, a perda de solo, ou seja, da sustentação do indivíduo arbóreo (SARAH; ZHEVELEV, 2007).

A espécie adequada em uma área superficial é uma premissa inicial (TYRVÄINEN et al., 2012). A arquitetura de crescimento vegetal necessita de uma avaliação, ou seja, se a espécie tem boa sustentação no solo (raízes profundas), se sua copa não expande tridimensionalmente de forma demasiada, se seus frutos não serão pesados ou se provoquem uma coloração distinta na superfície em que haja contato, se suas raízes não danifiquem os calçamentos e vias públicas (HEIKURA et al., 2008). Caso a espécie não seja a adequada, fatores de minimização de impactos devem ser aplicados, como o respeito as normas técnicas municipais para implementação de construções e de árvores, por exemplo, observar a altura mínima para redes de baixa tensão (> 7,20 m) e a distância mínima construções urbanas deverão ter dos indivíduos arbóreos (4 m) (MINHOTO et al., 2009; SMAS, 2013). Outros fatores devem ser considerados, como a erradicação dos insetos ou espécies que causam escarificação, ocos e brocagem nos indivíduos arbóreos (SARAH; ZHEVELEV, 2007). 96\% das árvores que caem nas regiões metropolitanas possuem um grau de dano causado por inseto ou animais (LAĆAN; MCBRIDE, 2008). 
Revista Tecnologia e Sociedade, Curitiba, v. 11, n. 23, 2015

ISSN (versão online): 1984-3526

ISSN (versão impressa): 1809-0044

Independente destes fatores, o planejamento dos novos espaços urbanos ou o manejo dos espaços já existentes é necessário para que haja um controle nas quedas dos indivíduos arbóreos e seus decorrentes danos (MELO et al. 2013; MAIOR et al., 2013). Porém, a preocupação deste trabalho não é o dano causado pelas árvores, e sim com a sua coexistência no ambiente urbano, recebendo manejo a partir de diagnósticos participativos pela sociedade. Dados indicaram que o investimento no plantio e no manejo dos indivíduos arbóreos (podas, desbastes e pulverização de inseticidas naturais) reduzem os custos com indenizações decorrentes de danos dos indivíduos arbóreos, aumentam a beleza cênica da cidade e eliminam quebra e rachaduras nas vias públicas (SKÄRBÄCK, 2007). Estes tópicos são utilizados na avaliação da qualidade da vida urbana, sendo expressa através do índice de área verde, índice importante economicamente pela atração de um turismo, moradores e investidores (DUVEILLER et al., 2011).

Empresas especializadas para o diagnóstico e manejo das árvores urbanas foram difundidas, realizando a interface entre o poder público e a sociedade, atuando segundo normas, resoluções técnicas e certificações de qualidade. Porém, esta interface distancia a responsabilidade do poder público das ações e desejos comunitários (CARNEIRO JUNIOR; NASCIMENTO; COSTA, 2011; ROBERTSON, 2012). Com o aprimoramento e acesso dos meios de comunicação, esta relação se tornou direta, faltando a sociedade ferramentas para a análise da infraestrutura urbana, através de parâmetros especializados (PEIXOTO; MARSIGLIA; MORRONE, 2013). A partir de então, iniciativas individuais, de certos grupos sociais e empresariais, começaram a criar ferramentas de análise urbana, disponíveis de forma gratuita e de fácil manejo e interpretação (KOCHA; KERSCHBAUMB, 2014). Vários exemplos podem ser explicitados, uns deles são: os geoambientes e ferramentas de análise disponíveis pelo Google (2014): GoogleMaps e GoogleEarth; os sites e blogs especializados, juntamente com as vídeos-aulas (Youtube); e, por último, os aplicativos, nesta mesma corrente.

Os aplicativos, neste contexto, simplificaram os diagnósticos iniciais, apesar de estimar dados análises, e ter alguns desvios e distintas calibragens, porém as repostas dadas pelos aplicativos pôde guiar: i) a livre iniciativa, com a ampliação de mercado e estabelecimentos de nichos comerciais; ii) o gestor público, como forma de monitoramento, comunicação e resolução de problemas públicos; e iii) a 
Revista Tecnologia e Sociedade, Curitiba, v. 11, n. 23, 2015

ISSN (versão online): 1984-3526

ISSN (versão impressa): 1809-0044

sociedade, nas tomadas de decisão em cima de suas demandas (HSIEHA; HSIEH, 2013). De 2012 para 2013, houve um aumento mundial de 115\% do uso de aplicativos em dispositivos móveis (FLURRY, 2014). Os diagnósticos são construídos a partir de uma 'árvore de decisão', ou algoritmo, que é denominada de uma sequência finita de instruções definidas e não ambíguas, sendo executada mecanicamente (UHL, 2012), indo a direção de uma tomada de decisão.

Com a posse dos diagnósticos apresentados pelos aplicativos, e com uma reivindicação em mão, e a não resposta e solução por parte do poder público, podem ocorrer então as Mobilizações Sociais. Estas mobilizações podem ser institucionalizadas, com uma amplitude significativa, ou por sua extensão ou por sua significação, como a criação das organizações não governamentais (ONGs) e associações (eg. Associação Brasileira de Gays, Lésbicas e Transgêneros, Doutores da Alegria, Comissão Pastoral da Terra), através de fóruns (eg. Fórum Social Mundial, Fórum Nacional de Mulheres Negras, Fórum Nacional de Reforma Agrária, Fórum do Lixo e Cidadania, Articulação das Mulheres Brasileiras, Fórum Nacional de Prevenção e Erradicação do Trabalho Infantil), através de redes (eg. Inter-redes Direitos e Políticas, Rede Cerrado, Rede Mata Atlântica e Rede de Informação do Terceiro Setor), redes transnacionais (Consejo de Educación de Adultos de América Latina; Coalizão Rios Vivos, Via Campesina; Movimento Indígena), das marchas e protestos (eg. Marcha Nacional da Reforma Agrária, Marcha da Reforma Urbana, Marcha Mundial das Mulheres, Marcha da Maconha, Marcha Zumbi +10, Parada do Orgulho Gay, Diretas Já, Impeachment do Presidente Collor e Revoltas de Junho). Há também os movimentos sociais de base locais, que possuem uma reivindicação social espacialmente regionalizada (eg. FlashMob culturais, protestos e obstrução de vias públicas), porém que agrega as causas globais (SCHERER-WARREN, 2013; NOBRE, 2013).

A mobilização na esfera pública ou mobilização social (SCHERER-WARREN, 2006) são frutos da articulação de atores de movimentos sociais (ativistas) ou atores individuais pertencentes a vários círculos sociais (MARTUCCELLI, 2012) simpatizantes a uma causa ou que possuam uma identidade, um 'adversário' (sistemas antagônicos que deve ser combatidos) e um projeto em comum (TOURAINE, 1978). A união destes atores busca produzir visibilidade através da mídia e seus efeitos simbólicos desejados, pressionando o poder público e as 
Revista Tecnologia e Sociedade, Curitiba, v. 11, n. 23, 2015

ISSN (versão online): 1984-3526

ISSN (versão impressa): 1809-0044

respostas sociais e individuais (NOBRE, 2013), e implementando uma prática político-pedagógica (TOLEDO; GIATTI; PELICONI, 2012).

A função da Educação neste contexto é fundamental para afinar o projeto em comum e os métodos, na qual se atingirão os objetivos, que é o efeito simbólico e o concreto (TOLEDO; GIATTI; PELICONI, 2012). Por exemplo, as ONGs, como SOS Mata Atlântica (2014) e Doutores da Alegria (2014) capacitam seus atores e os inserem em discussões temáticas críticas para a construção do conhecimento, antes de suas mobilizações, para embasamento da causa e como irão conseguir seus efeitos. Outros exemplos eficientes que também utilizaram a educação como base de seus movimentos sociais, foram as de equipes sanitárias, que utilizaram a participação popular de comunidades tradicionais para sanar temáticas referentes a saúde (TOLEDO; GIATTI; PELICONI, 2012), e projetos de regeneração urbana, como o movimento 'Okupa', realizado em Madrid (ADELL; MARTINEZ, 2004).

Com isso, o objetivo deste trabalho foi reduzir o número árvores que caem e provocam danos em ambientes urbanos na cidade do Recife, visando sua coexistência no espaço público, através do uso da tecnologia (um aplicativo), da educação e da mobilização social.

\section{MATERIAIS E MÉTODOS}

O método utilizado seguiu três passos (Figura 1). O primeiro foi a construção de um aplicativo que classifica o risco que o indivíduo arbóreo representa para alguma estrutura urbana (rede elétrica, construção, via pública, e outros), e, que posteriormente aciona o órgão competente para manejo do indivíduo arbóreo. Em seguida, houve a capacitação para o uso do aplicativo e a apresentação dos operadores teóricos para sua mobilização. E, por fim, a mobilização social com a disseminação do uso do aplicativo e as análises da mobilização. 
Revista Tecnologia e Sociedade, Curitiba, v. 11, n. 23, 2015

ISSN (versão online): 1984-3526

ISSN (versão impressa): 1809-0044

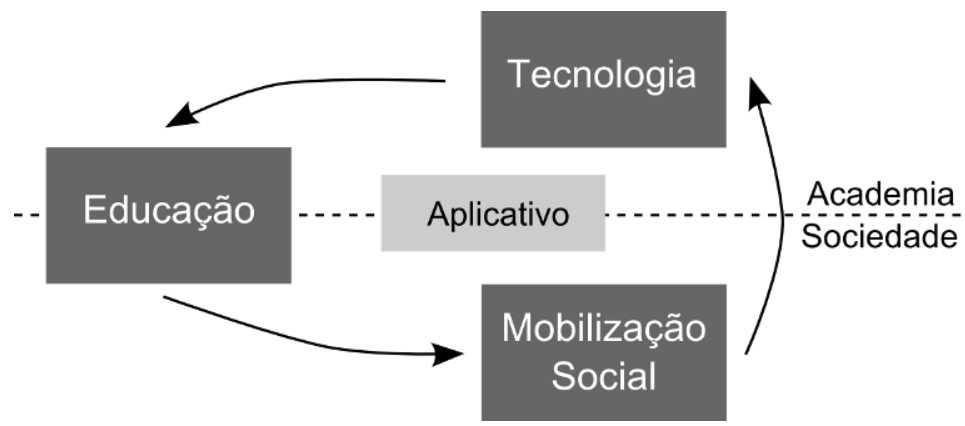

Figura 1 - Tripé metodológico utilizado para atingir os objetivos. Fonte: Elaborada pelo autor.

O aplicativo classifica o indivíduo arbóreo quanto seu risco a danos urbanos, em: i) sem risco, ii) baixo risco, iii) médio risco, e, iv) alto risco (SANI et al., 2012). Ele foi construído na base MIT App Inventor (2013) com um algoritmo, 'árvore de decisão', utilizando as variáveis: proximidade da estrutura urbana (rede e instalações elétricas, construções, via, e outras), posicionamento geográfico (Sistema de Posicionamento Global - SAD69), e as variáveis biométricas para a árvore analisada: altura da copa, diâmetro da copa, e presença de oquidão e / ou insetos. O algoritmo de decisão foi construído a partir do ranqueamento das variáveis independente em termos de qual a que delas, isoladas ou em conjunto (NEWTON, 2012), causariam efeitos diretos e imediatos as estruturas urbanas. A partir dos critérios técnicos (SMAS, 2013), foram estabelecidas alturas, distâncias e tamanhos mínimos para que as árvores fossem classificadas como risco ou não. $\mathrm{O}$ aplicativo pode ser abaixado através do link: http://goo.gl/Qkgj07.

O indivíduo social acrescenta os dados ao aplicativo, referentes as variáveis mencionadas, na qual classifica automaticamente o grau de risco. Os dados quanto acionados para a classificação vão para um Banco de Dados: 'ArvUrb DataBase', e, caso o risco do indivíduo for médio ou alto, um e-mail automaticamente é enviado ao órgão municipal competente, que no caso é a Empresa de Manutenção e Limpeza Urbana de Recife (EMLURB, 2013), com a posição geográfica e um diagnóstico preliminar de poda, para médio risco, e erradicação e substituição da árvore, para alto risco. A EMLURB é a responsável, após seu acionamento, de confirmar todos diagnósticos enviados via ouvidoria pública, através de Pareceres Técnicos internos.

Para alimentar o aplicativo, o observador pode mensurar as variáveis de maneira direta, como fita métrica ou outra ferramenta, e também pela opção de estimar as variáveis através de outros aplicativos auxiliares, podendo ser adquiridos 
Revista Tecnologia e Sociedade, Curitiba, v. 11, n. 23, 2015

ISSN (versão online): 1984-3526

ISSN (versão impressa): 1809-0044

gratuitamente no 'Play Store', para dispositivos móveis Android; e no 'Apple Store', para iPhone; como Telêmetro (Smart Tools co.) para medir distâncias, o 'Hypsometer' (Makinosoft) para mensurar a altura da árvore, e o Bitterlich (Deskis OÜ) para mensurar o diâmetro da copa. A qualificação da presença e ausência de oquidão e dos insetos foram caracterizadas visualmente, sendo que a presença de insetos se refere a aqueles que por algum motivo trazem danos ao tronco das árvores (insetos brocadores) (GARCIA, 2007).

O aplicativo foi gerado em sua versão beta em março de 2011, e finalizado em maio de 2011, quando foi divulgada à sociedade (http://goo.gl/Qkgj07). A partir daí cursos de extensão sistemáticos a cada dois meses foram realizados com as comunidades residentes na área de estudo. A área avaliada corresponde a seis regiões no Município de Recife, Pernambuco (Figura 2), na qual foram estabelecidas de maneira aleatória e dispersa, áreas circulares que englobassem distintos bairros, com diferentes formas de ocupação e características socioeconômicas (RECIFE, 2011). A área total avaliada foi de $24.028 \mathrm{~km}^{2}$, representando $11 \%$ do total de $218.435 \mathrm{~km}^{2}$ de Recife.
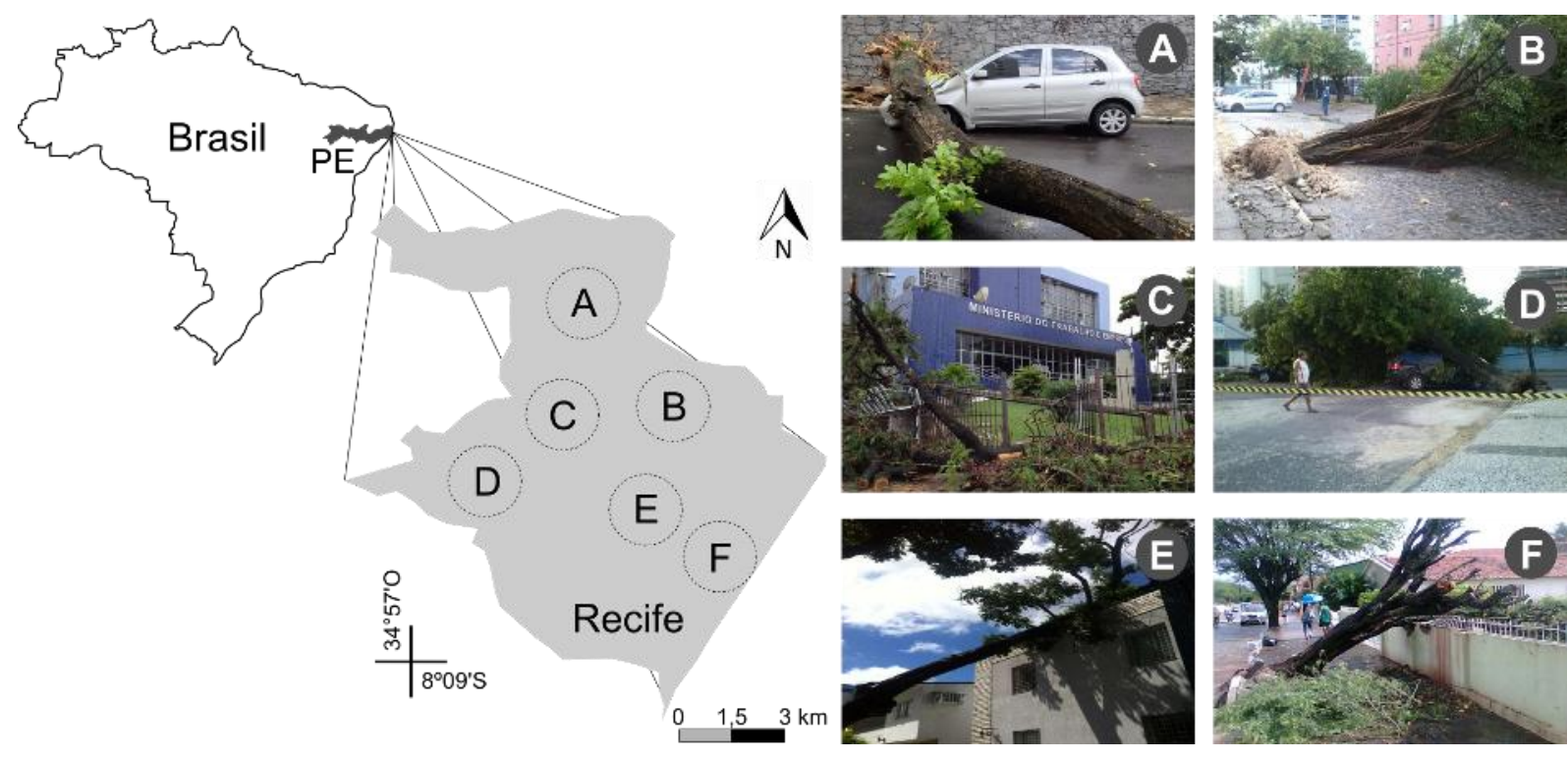

Figura 2 - Áreas mobilizadas para estudo (A a F) e eventos de quedas de árvores no período de estudo Fonte Figura: Elaborada pelo autor. Fotos reproduções: A) K. Marinho; B) A. C. Dolores; C) T. Maia; D e E) R. Silva; e F) J. P. Lima.

Os cursos trataram não só da capacitação e disseminação do uso do aplicativo, como também da discussão da pergunta: "Como uma mobilização social poderia influir na eficiência da gestão municipal, no bem estar e redução de danos 
Revista Tecnologia e Sociedade, Curitiba, v. 11, n. 23, 2015

ISSN (versão online): 1984-3526

ISSN (versão impressa): 1809-0044

urbanos?" No total de 4 horas, os cursos ocorreram no último sábado de cada bimestre, de maio de 2011 a outubro de 2012, sendo os locais, em sedes comunitárias: bibliotecas públicas, escolas públicas e privadas, igrejas e centros culturais, localizadas na Figura 2, nas áreas de A a F. A partir do curso foram mobilizadas pessoas que, por voluntarismo, pudessem instalar em seus dispositivos móveis (celular ou tabletes) o aplicativo e o seu respectivo compartilhamento. Os operadores teóricos utilizados para o curso foram: Touraine (1978); Scherer-Warren (2006); Orueta (2007); Toro e Werneck (2007); e Plano de Mobilização Social Pela Educação - PMSE (2011). A pergunta inicial foi refeita ao final do curso para que todos os cursistas respondessem de forma escrita, e sendo avaliadas as respostas chave (démarches) ao final da análise dos dados (BILLOUET, 2007; BARDIN, 2011).

Para análise do sucesso da mobilização, dois períodos foram avaliados: i) antes, de maio de 2011 a outubro de 2012, em que ocorreram os cursos e a disseminação do aplicativo nas redes de comunicação; e ii) depois, de novembro de 2012 a abril de 2014, na qual os usuários dos aplicativos classificaram as árvores quanto ao risco e o órgão público foi mobilizado. Ao final, um questionário foi aplicado aos usuários, avaliando em uma escala Likert (1932) de satisfação (de um a dez), sobre a utilização e resultado do uso do aplicativo. Um teste não paramétrico $x^{2}$ foi aplicado entre o número total de indivíduos arbóreos que caíram e causaram danos antes e depois da disseminação do aplicativo.

\section{RESULTADOS E DISCUSSÃO}

A árvore de decisão (Figura 3A) base para o aplicativo construído (Figura 3B) foi sistematizada a partir das variáveis estabelecidas. O aplicativo foi instalado em aproximadamente 7 mil (6.898) aplicativos móveis de maio de 2011 a outubro de 2012, participando do curso de capacitação e embasamento para mobilização aproximadamente 1,5 mil (1.452) alunos nas áreas avaliadas, nas cinco áreas avaliadas (Figura 4). Dos que participaram do curso e usuários do aplicativo, 636 responderam ao questionário (Figura 4) de satisfação de uso e resultado do aplicativo, e aproximadamente $99 \%$, ou seja, 632 pessoas classificaram a utilização do aplicativo como satisfatória (peso $>7$ ). 
Revista Tecnologia e Sociedade, Curitiba, v. 11, n. 23, 2015

ISSN (versão online): 1984-3526

ISSN (versão impressa): 1809-0044

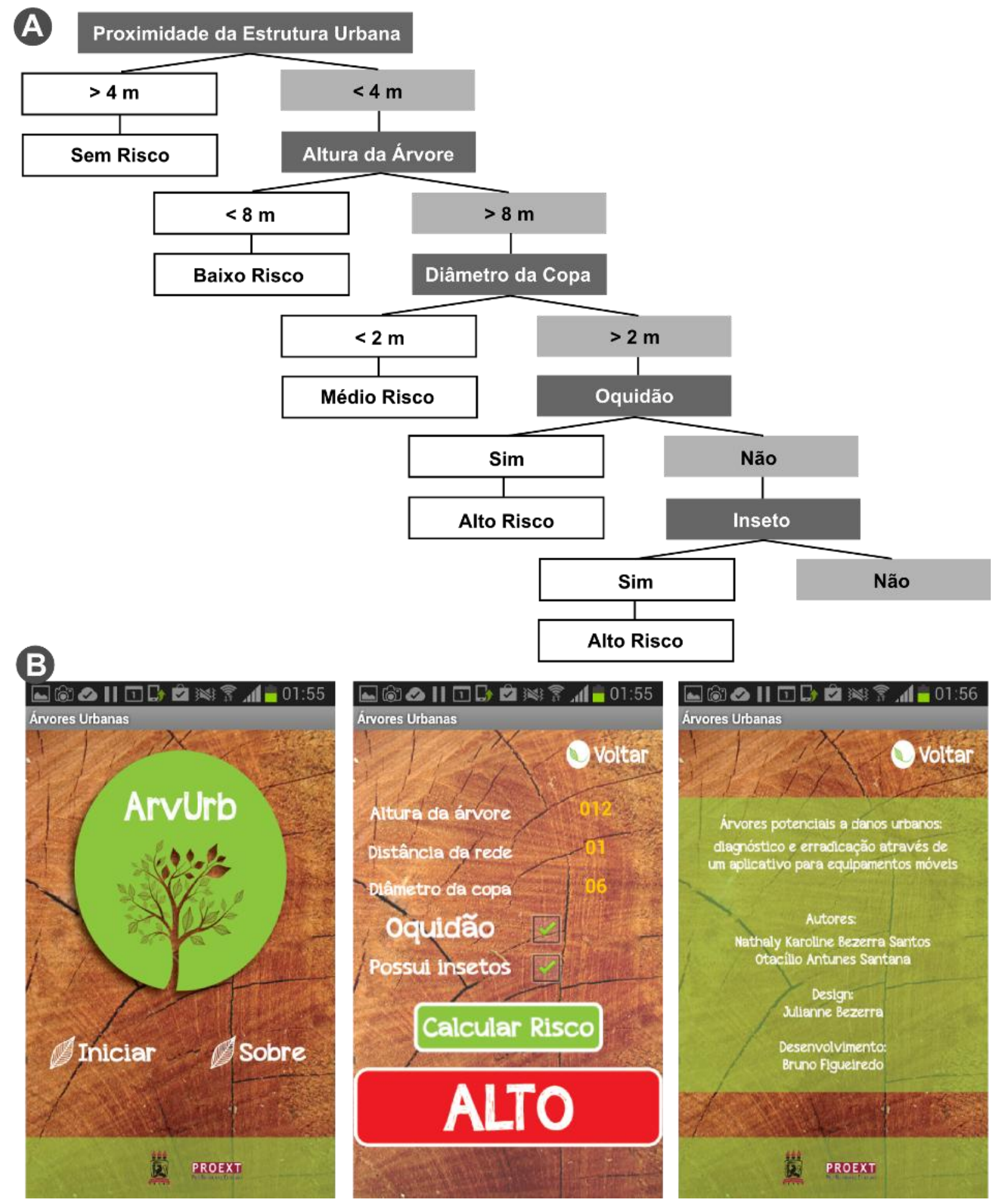

Figura 3 - A) Árvore de Decisão para classificação do risco a danos urbanos pelas árvores, e B) o layout do Aplicativo 'ArvUrb'. Fonte: Elaborada pelo autor. 
Revista Tecnologia e Sociedade, Curitiba, v. 11, n. 23, 2015

ISSN (versão online): 1984-3526

ISSN (versão impressa): 1809-0044
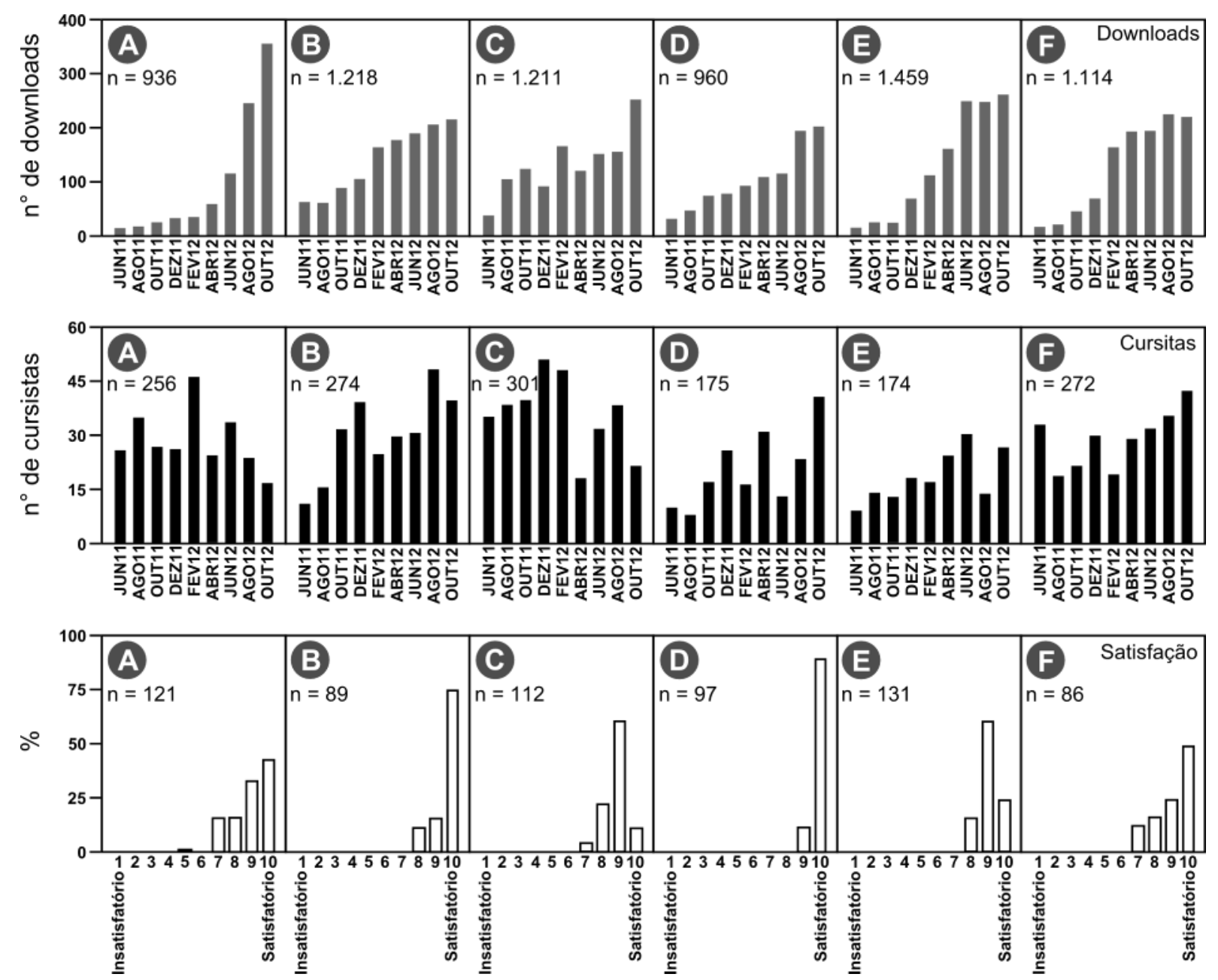

Figura 4 - Número de downloads do aplicativo e cursistas capacitados e mobilizados (de maio de 2011 a outubro de 2012); e satisfação de uso do aplicativo e seus resultados, nas áreas avaliadas (de A a F). Fonte: Elaborada pelo autor.

O total de árvores classificadas pelo aplicativo foi de 1.802 , sendo 74 classificadas como 'Sem Risco', 169 como 'Baixo Risco', 227 como 'Médio Risco', e 120 como 'Alto Risco', ou seja, 59\% dos indivíduos arbóreos das áreas amostradas necessitavam imediatamente de podas, erradicação e substituição (Figura 5). Das árvores mobilizadas pela participação popular no uso do aplicativo, 913 (de 1.802) tiveram algum manejo pelo órgão competente. 776 árvores foram podadas e 137 foram erradicadas e substituídas (Figura 5).

Com isso, o número de árvores com queda total ou parcial que causou algum dano a estruturas urbanas reduziram em todas as cinco áreas avaliadas de forma significativa ( $\left.p<0,001 ; \chi^{2}=44,30\right)$, de antes, 71 árvores caíram, fase de divulgação do aplicativo e do curso (maio de 2011 a outubro de 2012), a depois (de novembro de 2012 a abril de 2014), 11 árvores (Figura 5). 
Revista Tecnologia e Sociedade, Curitiba, v. 11, n. 23, 2015

ISSN (versão online): 1984-3526

ISSN (versão impressa): 1809-0044
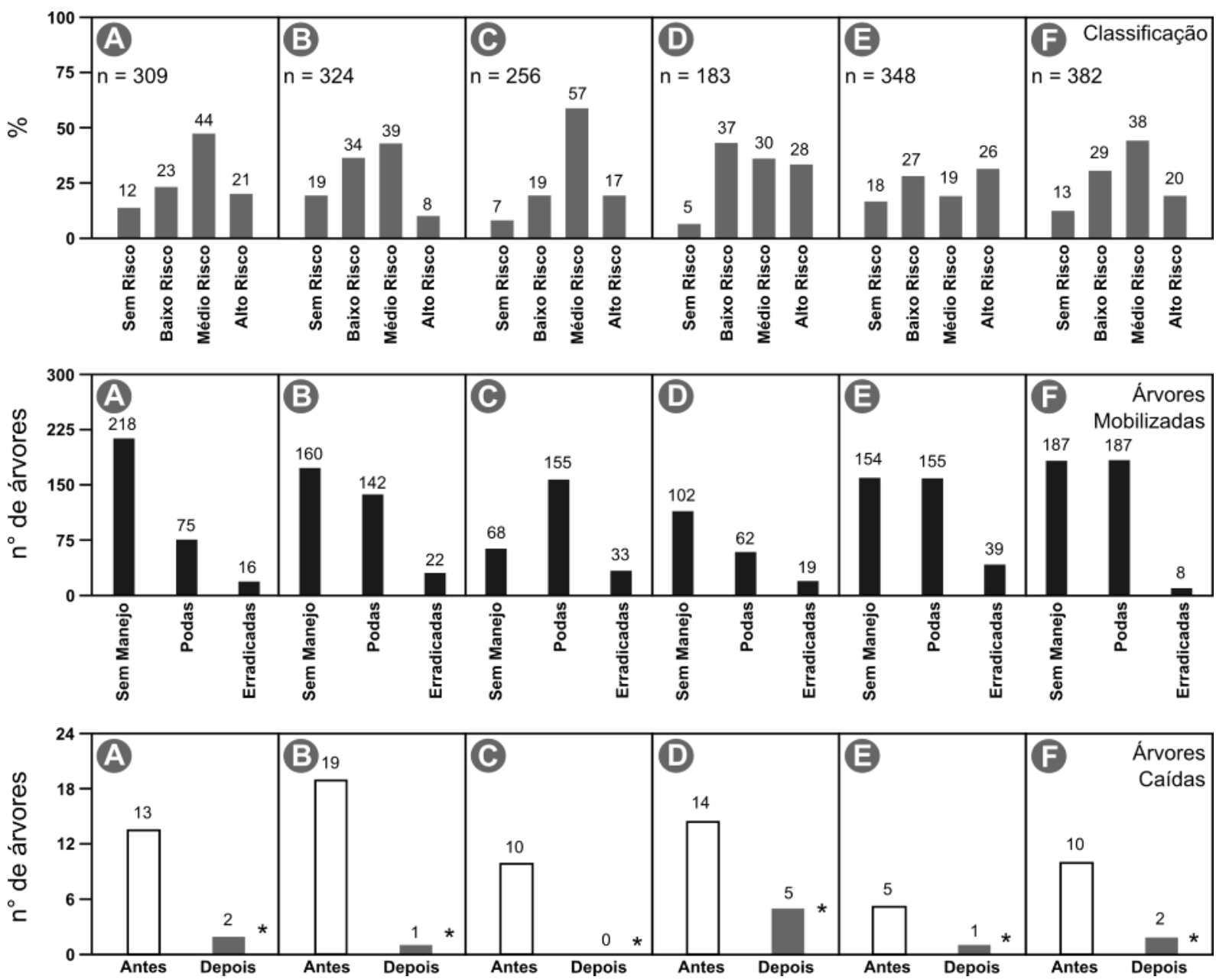

Figura 5 - Árvores classificadas com o aplicativo, mobilizadas (de novembro de 2012 a abril de 2014), e número de quedas, antes (de maio de 2011 a outubro de 2012) e depois (de novembro de 2012 a abril de 2014) da disseminação do aplicativo (de A a F). *Diferença significativa $p<0,001$.

Fonte: Elaborada pelo autor.

Os dados indicaram que o tripé utilizado: tecnologia, educação e mobilização foram eficazes e eficientes. Em 18 meses (de novembro de 2012 a abril de 2014), houve a redução de $85 \%$ de queda de árvores nas áreas avaliadas. Este dado nos remeteu à questão apresentada no curso: Como uma mobilização social poderia influenciar na eficiência da gestão municipal, no bem-estar e redução de danos urbanos?, na qual os démarches sintetizados dos relatos cursistas foram cinco:

(i) "A coletivização de uma demanda urbana passa de uma cobrança individual para uma ação conjunta."

Este primeiro tópico ressalta a importância da coesão social (DURKHEIM, 2007). E este relato explicita a solidariedade orgânica caracterizada por ser aquela em que o consenso resulta de uma diferenciação, os indivíduos não se agrupam por seus em valores, religiões e éticas, e sim a partir da dependência que um tem do outro para realizar alguma atividade social. Daí busca o direito cooperativo, cuja 
Revista Tecnologia e Sociedade, Curitiba, v. 11, n. 23, 2015

ISSN (versão online): 1984-3526

ISSN (versão impressa): 1809-0044

essência não é a punição das violações das regras sociais, mas organizar a cooperação entre os indivíduos (DURKHEIM, 2010). Para o objetivo proposto esta coesão se mostrou fundamental.

(ii) "Mais atores associados podem produzir um eco maior da questão objetivada. E mais atores envolvidos podem produzir resultados."

O segundo tópico assinalado, e consequente do primeiro, foi que a união de atores em termos quantitativos pode produzir efeitos qualitativos, ou seja, resultados. As respostas, neste sentido, retrataram que a demanda quando requisitada por um número maior de pessoas ecoa nos órgãos públicos de maneira significativa, havendo uma inversão de poder em que o direito sobressai sobre o dever, e, nesse momento, o poder público tem como pauta principal executar a demanda da sociedade (TOURAINE, 1978). O exemplo, para isso, foram as Revoltas de Junho, ocorridas em 2013, em que aproximadamente 2 milhões de pessoas participaram de manifestações em 438 cidades brasileiras, isto apenas dia 20 de junho de 2013, inicialmente focados pela redução da tarifa do transporte público em 20 centavos (no caso de São Paulo), mas com outras reinvindicações, que prontamente foram atendidas por governadores e prefeitos (NOBRE, 2013). O número de download e usuários do aplicativo chegou a aproximadamente 7 mil, representativo para a área avaliada neste trabalho $\left(24.028 \mathrm{~km}^{2}\right)$.

(iii) "A sociedade vê, sente, está em contato e diagnostica o problema, podendo ela (a sociedade) prevenir, acionar os órgãos competentes ou remediar em tempo hábil."

Pequenas demandas sociais como a manutenção de uma praça, requisição de proteção em caso de suspeita de insegurança, eliminação de focos de doenças, e projetos de educação popular podem ser iniciadas por qualquer cidadão e em conjunto. A participação deste está na legislação brasileira como a 'ação popular', na qual qualquer cidadão será parte legítima para pleitear a anulação ou a declaração de nulidade de atos lesivos ao patrimônio do bem público (BRASIL, 1965), e da 'iniciativa popular' que consiste na apresentação de projeto de lei à Câmara dos Deputados, subscrito por uma representatividade eleitoral e regional (BRASIL, 1998). Este papel de 'observatório' se torna importante, pois aponta o problema urbano, discute, e, às vezes, direciona o poder público a uma solução. O exemplo disto têm-se alguns observatórios, tais como: o Observatório da Imprensa (2014), 
Revista Tecnologia e Sociedade, Curitiba, v. 11, n. 23, 2015

ISSN (versão online): 1984-3526

ISSN (versão impressa): 1809-0044

Observatório do Recife (2014), Observatório do Código Florestal (2014), Observatório Universitário (2014), Observatório do Direito a Comunicação (2014), e outros. A mobilização social através do aplicativo, no caso deste trabalho, representou este tipo de observatório.

(iv) "A tecnologia se tornou indispensável nas cidades, veio para facilitar a troca de informações entre os cidadãos."

Este relato mostra que com a popularização de tecnologias informação e comunicação (TICs), principalmente dos dispositivos móveis, facilitou o contato entre indivíduos e a convergências sociais por este contato, por diversas causas (familiares, amizade, profissionais, etc.) (SCHERER-WARREN, 2006). Esta tecnologia, como expressa no relato, transformou de forma dependente as mobilizações sociais aos movimentos que se integram em redes (SCHERERWARREN, 2013), e neste caso, a ferramenta acrescenta uma particularidade a ação individual e social (MCLUHAN, 1964), facilitando o acesso e a manutenção do indivíduo em diversos círculos sociais (MARTUCCELLI; SINGLY, 2012). O indivíduo pode ser um multiativista e participar de vários 'observatórios' (SCHERERWARREN, 2013). Porém, para ter uma voz ativa dentro dos círculos sociais, é necessário que o indivíduo construa seu conhecimento sobre a temática da rede, para se embasar para as discussões e enfrentamento do problema urbano (TOLEDO; GIATTI; PELICIONI, 2012). Os aplicativos, como o construído neste trabalho, poderão ser uma ferramenta de gestão urbana imprescindível.

(v) "A educação já direcionava a uma mobilização. A junção da educação com a tecnologia, para a análise de um parâmetro urbano, fez transformar os dados e as observações em uma ação concreta."

O último démarche se agrega ao anterior, e é o momento em que a educação, neste caso, a elucidação para análise de um diagnóstico, reflete no ser, tornando-o crítico frente a questões da polis (do espaço urbana) (FREIRE, 2002). Paulo Freire descreveu que todo ato de educar é um ato político, justamente por dar visão e ferramentas para o debate frente a classe gestora urbana (FREIRE, 2006). É importante salientar também o momento em que os dados ou as informações avulsas se tornam em um processo de formação para os indivíduos, que conseguem analisar diagnósticos e a tomarem decisões a partir daí (CABRAL, 2012).

\section{CONSIDERAÇÕES FINAIS}


Revista Tecnologia e Sociedade, Curitiba, v. 11, n. 23, 2015

ISSN (versão online): 1984-3526

ISSN (versão impressa): 1809-0044

O objetivo do trabalho foi atingido, houve a redução de árvores caídas, que resultavam em danos urbanos. O tripé metodológico que juntou a tecnologia, educação e mobilização social foi eficiente para não só no período do trabalho, mas para sua constante utilização pela sociedade. Eficiência requerida na gestão do ambiente para redução de gastos com manutenção e remediação de danos. Este método motiva a aplicação em outras áreas temáticas urbanas e ambientais, como a saúde, a minimização de impactos ambientais, a valorização de comunidades tradicionais e culturais, e outros.

O aplicativo construído foi de fácil obtenção e utilização, visto pelo resultado da satisfação de uso. Os usuários de diferentes idades, classes sociais e culturais não sentiram obstáculos em seu uso quanto a complexidade. Tanto o número de usuários, quanto o de cursistas e o de árvores mobilizadas foram significativas para a área avaliada e pelo resultado obtido. Alguns cursistas tomaram consciência da importância do indivíduo e de sua mobilização para uma ação urbana, e a força que tem suas demandas frente a uma crise de representatividade institucional e a uma perda de tradição objetiva e subjetiva, presentes na pós-modernidade.

Com isso, a construção de uma identidade para causas em comuns no âmbito urbano, ambiental e social, a elaboração de um método de desconstrução de 'adversários' (queda de árvores), e o projeto em comum para constante luta (coexistência de árvores no ambiente urbano), mostra a força social diante da democracia e a geração de resultados que beneficiam o ambiente e a sociedade.

A perspectiva de novos trabalhos está pautada no aperfeiçoamento do aplicativo quanto a linguagem, divulgação, comunicação e implementação a vários sistemas operacionais, em que é auspicioso parcerias pública-privada (universidades e startups; órgãos públicos e sistemas de comunicação, e.g. empresas de telefonia) e pública-pública (órgãos federais, estaduais e municipais), para que um grupo maior de especialistas possam refinar ou agregar funções a ele. Outros detalhes técnicos poderão ser estabilizados, como a calibração do GPS (sistema de posicionamento global) do dispositivo móvel, e o acréscimo de classificações automáticas de riscos por agregação de técnicas de sensoriamento remoto. Novos arranjos poderão ser adicionados ao algoritmo, como a proximidade a empreendimentos da construção civil, que causam, na maioria dos casos, o movimento na textura do solo e subsolo, o que resulta na perda de sustentação da 
Revista Tecnologia e Sociedade, Curitiba, v. 11, n. 23, 2015

ISSN (versão online): 1984-3526

ISSN (versão impressa): 1809-0044

árvore, na qual é registrado que próximos a essas construções, após a conclusão da obra, há um aumento de registros de quedas de indivíduos arbóreos.

\section{REFERÊNCIAS}

ADELL, R.; MARTINEZ, M. (eds.) ¿Donde están las llaves? El movimento ocupa. Práticas y contextos sociales. Madrid: Los Libros de la Catarata. 2004. 352p.

BARDIN, L. Análise de conteúdo. São Paulo: Edições 70, 2011. 279 p.

BILLOUET, P. (org.) Débattre: Pratiques scolaires et démarches éducatives. Paris: L'Harmattan. 358p.

BRASIL. Regula a ação popular. Lei no 4.717, de 29 de junho de 1965. Disponível em < http://www.planalto.gov.br/ccivil_03/leis/14717.htm >. Acesso em Fev 2014.

BRASIL. Regulamenta a execução do disposto nos incisos I, II e III do art. 14 da Constituição Federal. Lei no 9.709, de 18 de novembro de 1998. Disponível em < http://www.planalto.gov.br/ccivil_03/leis/19709.htm >. Acesso em Fev 2014.

CABRAL, M. S. A. Reinventando a educação: diversidade, descolonização e redes. 518. ed. Petrópolis/RJ: Editora Vozes Ltda, 2012. v. 1. 279p.

CARNEIRO JUNIOR, N.; NASCIMENTO, V. B.; COSTA, I. M. C. Relação entre Público e Privado na Atenção Primária à Saúde: considerações preliminares. Saúde e Sociedade, v. 20, n. 4, Dec. 2011.

DOUTORES DA ALEGRIA. Escola. Disponível em: < www.doutoresdaalegria.org.br>. Acesso em Maio 2014.

DURKHEIM, E. Educação e sociologia. Lisboa: Edições 7O, 2007. 131p.

DURKHEIM, E. Da divisão do trabalho social. 4.ed. São Paulo: Martins Fontes, 2010. 483 p. (Coleção tópicos)

DUVEILLER, G.; WEISS, M.; BARET, F.; DEFOURNY, P. Retrieving wheat Green Area Index during the growing season from optical time series measurements based on neural network radiative transfer inversion. Remote Sensing of Environment, v. 115, n. 3, p. 887896, 2011.

EMLURB - Empresa de Manutenção e Limpeza Urbana de Recife. Serviços. Disponível em <http://www.recife.pe.gov.br/emlurb>. Acesso em Jan 2013.

FREIRE, P. Pedagogia do oprimido. 26.ed. São Paulo: Paz e Terra, 1987. 184 p.

FREIRE, P. Pedagogia da autonomia: saberes a pratica educativa. 23. ed. -. São Paulo: Paz e Terra, 2002. $165 \mathrm{p}$.

FLURRY. Mobile Use Grows 115\% in 2013, Propelled by Messaging Apps. Disponível em <http://www.flurry.com/>. Acesso em Jan 2014.

GARCIA, A. H. Levantamento, identificação e avaliação dos danos de insetos em árvores ornamentais na área urbana de Goiânia (GO). Pesquisa Agropecuária Tropical, v. 29, n. $1,2007$.

GOOGLE. Google Tools. Disponível em: <http://google.com>. Acesso em Fev 2014. 
Revista Tecnologia e Sociedade, Curitiba, v. 11, n. 23, 2015

ISSN (versão online): 1984-3526

ISSN (versão impressa): 1809-0044

HORÁK, J. Response of saproxylic beetles to tree species composition in a secondary urban forest area. Urban Forestry \& Urban Greening, v. 10, n. 3, p. 213-222, 2011.

HEIKURA, T.; TERHO, M.; PERTTUNEN, J.; SIEVÄNEN, R. A computer-based tool to link decay information to 3D architecture of urban trees. Urban Forestry \& Urban Greening, v. 7, n. 4, p. 233-239, 2008.

HLADNIK, D.; PIRNAT, J. Urban forestry-Linking naturalness and amenity: The case of Ljubljana, Slovenia. Urban Forestry \& Urban Greening, v. 10, n. 2, p. 105-112, 2011.

HSIEHA, J. K.; HSIEH, Y. C. Appealing to Internet-based freelance developers in smartphone application marketplaces. International Journal of Information Management, v. 33, p. 308-317, 2013.

JIM, C. Y. Monitoring the performance and decline of heritage trees in urban Hong Kong. Journal of Environmental Management, v. 74, p. 161-172, 2005.

KOCHA, S.; KERSCHBAUMB, M. Joining a smartphone ecosystem: Application developers' motivations and decision criteria. Information and Software Technology, v. 56, n. 8 p. 111, 2014.

LAĆAN, I.; MCBRIDE, J. R. Pest Vulnerability Matrix (PVM): A graphic model for assessing the interaction between tree species diversity and urban forest susceptibility to insects and diseases. Urban Forestry \& Urban Greening, v. 7, n. 4, p. 291-300, 2008.

LIKERT, R. A Technique for the Measurement of Attitudes. Archives of Psychology, v. 140, p. 1-55, 1932.

MAIOR, D. Q. S.; SANTANA, O. A.; INÁCIO, E. dos S. B.; AMORIM, L. B. de; ENCINAS, J. I. Diagnóstico da implantação de Eucalyptus grandis e Syzygium jambos no Campus da Universidade Federal de Pernambuco, através relação da idade com volume de madeira. Revista da Sociedade Brasileira de Arborização Urbana, v. 8, p. 35-45, 2013.

MARTUCCELLI, D.; SINGLY, F. Las Sociologías del Individuo. 1aㅡ ed. Santiago de Chile: LOM Ediciones (Colección Ciencias Humanas). 2012. 134 p.

MCLUHAN, M. Os meios de comunicação como extensões do homem. São Paulo: Cultrix, 1964. 407p.

MELO, I. J. M. ; SANTANA, O. A.; AMORIM, L. B.; Encinas, J. I. Influência da velocidade e direção do vento na espécie Cocos nucifera var. Typica (ARECACEAE) em áreas costeiras naturais e urbanas. Revista da Sociedade Brasileira de Arborização Urbana, v. 8, p. 8, 2013.

MINHOTO, E. S.; MONTEIRO, E. A.; FISCH, S. T. V. Arborização viária na cidade de Taubaté, SP: no Centro Comercial Histórico e um bairro residencial moderno. Revista da Sociedade Brasileira de Arborização Urbana, v. 4, n. 2, p. 82-96, 2009.

MIT App Inventor. Create. Disponível em <http://appinventor.mit.edu/>. Acesso em: Jan 2013.

NEWTON, P. F. A silvicultural decision-support algorithm for density regulation within peatland black spruce stands. Computers and Electronics in Agriculture, v. 80, p. 115-125, 2012.

NOBRE, M. Choque de Democracia: Razões da revolta. São Paulo: Companhia das Letras. 2013. 33 p. (Breve Companhia)

OBSERVATÓRIO DO CÓDIGO FLORESTAL. Página Inicial. Disponível em: < www.observatorioflorestal.org.br>. Acesso em: Fev 2014. 
Revista Tecnologia e Sociedade, Curitiba, v. 11, n. 23, 2015

ISSN (versão online): 1984-3526

ISSN (versão impressa): 1809-0044

OBSERVATÓRIO DO DIREITO À COMUNICAÇÃO. Página Inicial. Disponível em: < www.direitoacomunicacao.org.br>. Acesso em: Fev 2014.

OBSERVATÓRIO DA IMPRENSA. Página Inicial. Disponível em: < tvbrasil.ebc.com.br/observatorio >. Acesso em Fev 2014.

OBSERVATÓRIO DO RECIFE. Página Inicial. Disponível em: < http://www.observatoriodorecife.org.br/>. Acesso em Fev 2014.

OBSERVATÓRIO DO UNIVERSITÁRIO. Página Inicial. Disponível em: < www.observatoriouniversitario.org.br>. Acesso em Fev 2014.

ORUETA, F. D. Madrid: Urban regeneration projects and Social mobilization. Cities, v. 24, n. 3, p. 183-193, 2007.

PEIXOTO, S. F.; MARSIGLIA, R. M. G.; MORRONE, L. C. Atribuições de uma ouvidoria: opinião de usuários e funcionários. Saúde e Sociedade, v. 22, n. 3, 2013.

PERKINS, H. A. Gramsci in green: Neoliberal hegemony through urban forestry and the potential for a political ecology of praxis. Geoforum, v. 42, n. 5, p. 558-566, 2011.

PMSE - Plano de Mobilização Social pela Educação. Cartilha. Disponível em; < http://mse.mec.gov.br/>. Acesso em Jan 2011.

RECIFE, Pernambuco. Atlas Metropolitano. Disponível em: <http://www2.recife.pe.gov.br/>. Acesso em Abr 2011.

ROBERTSON, S. L. A estranha não morte da privatização neoliberal na Estratégia 2020 para a educação do Banco Mundial. Revista Brasileira de Educação, v. 17, n. 50, 2012.

SANI, L.; LISCI, R.; MOSCHI, M.; SARRI, D.; RIMEDIOTTI, M.; VIERI, M.; TOFANELLI, S. Preliminary experiments and verification of controlled pulling tests for tree stability assessments in Mediterranean urban areas. Biosystems Engineering, v. 112, n. 3, p. 218226, 2012.

SARAH, P.; ZHEVELEV, H. M. Effect of visitors' pressure on soil and vegetation in several different micro-environments in urban parks in Tel Aviv. Landscape and Urban Planning, v. 83, n. 4, p. 284-293, 2007.

SCHERER-WARREN, I. Das mobilizações às redes de movimentos sociais. Sociedade e Estado, v. 21, n. 1, p. 109-130, 2006.

SCHERER-WARREN, I. Redes e movimentos sociais projetando o futuro. Revista Brasileira de Sociologia, v. 01, p. 187-217, 2013.

SKÄRBÄCK, E. Urban forests as compensation measures for infrastructure development. Urban Forestry \& Urban Greening, v. 6, n. 4, 15 p. 279-285, 2007.

SMAS - Secretaria de Meio Ambiente e Sustentabilidade da Prefeitura da Cidade do Recife. Manual de arborização: orientações e procedimentos técnicos básicos para a implantação e manutenção da arborização da cidade do recife. 1. Ed. - Recife : Secretaria de Meio Ambiente e Sustentabilidade - SMAS, 2013. $71 \mathrm{p}$.

SOS MATA ATLÂNTICA. Projetos. Disponível em: <http://www.sosma.org.br/>. Acesso em Maio 2014.

TOLEDO, R. F.; GIATTI, L. L.; PELICIONI, M. C. F. Mobilização Social em Saúde e Saneamento em Processo de Pesquisa-ação em uma Comunidade Indígena no Noroeste Amazônico. Saúde e Sociedade, v.21, n.1, p.206-218, 2012. 
Revista Tecnologia e Sociedade, Curitiba, v. 11, n. 23, 2015

ISSN (versão online): 1984-3526

ISSN (versão impressa): 1809-0044

TORO, J. B.; WERNECK, N. Mobilização Social: um modo de construir a democracia e a participação. Belo Horizonte: Autêntica, 2007. 90p.

TOURAINE, A. La voix et le regard: Les mouvements sociaux. Paris: Les Éditions du Seuil, 1978, $315 \mathrm{p}$.

TYRVÄINEN, L.; GUSTAVSSON, R.; KONIJNENDIJK, C.; ODE, Å. Visualization and landscape laboratories in planning, design and management of urban woodlands. Forest Policy and Economics, v. 8, n. 8, p. 811-823, 2006.

YANG, J. Urban Forestry in Challenging Environments. Urban Forestry \& Urban Greening, v. 11, n. 2, p. 103-104, 2012. 